\title{
Oral antibiotic use and early-onset colorectal cancer: findings from a case-control study using a national clinical database
}

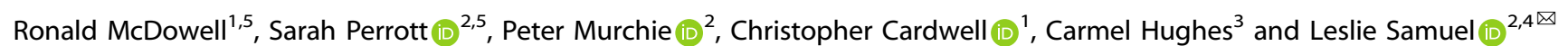

(c) The Author(s) 2021

BACKGROUND: Antibiotic-induced gut dysbiosis has been associated with colorectal cancer (CRC) in older adults. This study will investigate whether an association exists between antibiotic usage and early-onset colorectal cancer (CRC), and also evaluate this in later-onset CRC for comparison.

METHODS: A case-control study was conducted using primary care data from 1999-2011. Analysis were conducted separately in early-onset CRC cases (diagnosed $<50$ years) and later-onset cases (diagnosed $\geq 50$ years). Conditional logistic regression was used to calculate odds ratios and $95 \%$ confidence intervals $(\mathrm{Cl})$ for the associations between antibiotic exposure and CRC by tumour location, adjusting for comorbidities.

RESULTS: Seven thousands nine hundred and three CRC cases (445 aged $<50$ years) and 30,418 controls were identified. Antibiotic consumption was associated with colon cancer in both age-groups, particularly in the early-onset CRC cohort ( $<50$ years: adjusted Odds Ratio $\left(\mathrm{OR}_{\mathrm{adj}}\right) 1.49(95 \% \mathrm{Cl} 1.07,2.07), p=0.018 ; \geq 50$ years $\left(\mathrm{OR}_{\mathrm{adj}}(95 \% \mathrm{Cl}) 1.09(1.01,1.18), p=0.029\right)$. Antibiotics were not associated with rectal cancer $\left(<50\right.$ years: $\mathrm{OR}_{\text {adj }}(95 \% \mathrm{Cl}) 1.17(0.75,1.84), p=0.493$; $\geq 50$ years: $\mathrm{OR}_{\mathrm{adj}}(95 \% \mathrm{Cl}) 1.07(0.96,1.19)$, $p=0.238$ ).

CONCLUSION: Our findings suggest antibiotics may have a role in colon tumour formation across all age-groups.

British Journal of Cancer (2022) 126:957-967; https://doi.org/10.1038/s41416-021-01665-7

\section{BACKGROUND}

Since the late 1980s, global antibiotic consumption and cases of early-onset colorectal cancer (CRC) have increased markedly [1-3]. This pattern may be related; antibiotic consumption has been associated with CRC genesis in adults of all ages [4-8]. In contrast to declining incidence amongst older populations [5, 9], CRC incidence among adults aged 20-29 years in Europe is increasing by $\sim 8 \%$ each year [1]. In the USA, CRC is the second most common incident cancer and third leading cause of cancer death in adult males less than 50 years old [10]. Consensus exists that early-onset CRC ( $<50$ years) is different to later-onset CRC ( $\geq 50$ years) in terms of epidemiology, pathology and biology $[5,6,11]$, although more recent evidence suggests both types are clinically and genomically indishtinguishable [12]. Therefore, there may be a rationale for studying early-onset CRC separately from later-onset CRC to identify specific risk factors associated with the rising trend observed among younger people.

Worldwide, there were $\sim 70$ billion doses of antibiotics consumed in 2011-which equates to 10 per person on earth [13]. Although essential for many medical interventions, children and teenagers are amongst those most commonly exposed to antibiotic therapy [14] and may be more vulnerable to the potential effects of overexposure-such as obesity, allergic diseases and inflammatory bowel disease $[5,15]$. In the USA, $69 \%$ of children aged less than 2 years are exposed to antibiotics [16], and as accessibility to antibiotics increases across low and middle-income countries, antibiotic usage for common childhood infections is becoming more widespread [17, 18]. Furthermore, high prevalence of acne amongst adolescents can result in longterm antibiotic exposure, sometimes lasting months to years due to varying national guidelines and uncertainty regarding optimum treatment duration [19]. In addition, at least $20-30 \%$ of antibiotics prescribed in primary care may be inappropriate $[18,20]$.

The relationship between pathogenic organisms and cancer is well-established; Helicobacter pylori is associated with gastric cancer and human papilloma virus (HPV) with anal, cervical, tonsillar and vulval cancer [21, 22]. Antibiotic-induced microbiome changes can be permanent and irregularities in immunostimulatory bacterial products can impede normal immune-surveillance, increasing the risk of carcinogenesis [21]. In addition, interruption of normal gut commensals may allow colonisation by pathogenic bacteria, which invade and damage the gut mucosa, leading to inflammation and tumour formation [22]. Examples of these harmful microbes include strains of Escherichia. coli and Bacteroides. fragilis; which may be promoted by certain antibiotics $[22,23]$.

\footnotetext{
${ }^{1}$ Centre for Public Health, School of Medicine, Dentistry \& Biomedical Science, Queen's University, Belfast, Northern Ireland. ${ }^{2}$ School of Medicine, Medical Sciences and Nutrition, University of Aberdeen, Aberdeen, Scotland. ${ }^{3}$ School of Pharmacy, Queen's University, Belfast, Scotland. ${ }^{4}$ Department of Clinical Oncology, Aberdeen Royal Infirmary, NHS Grampian, Aberdeen, Scotland. ${ }^{5}$ These authors contributed equally: Ronald McDowell, Sarah Perrott. ${ }^{{ }}$email: leslie.samuel@nhs.scot
} 


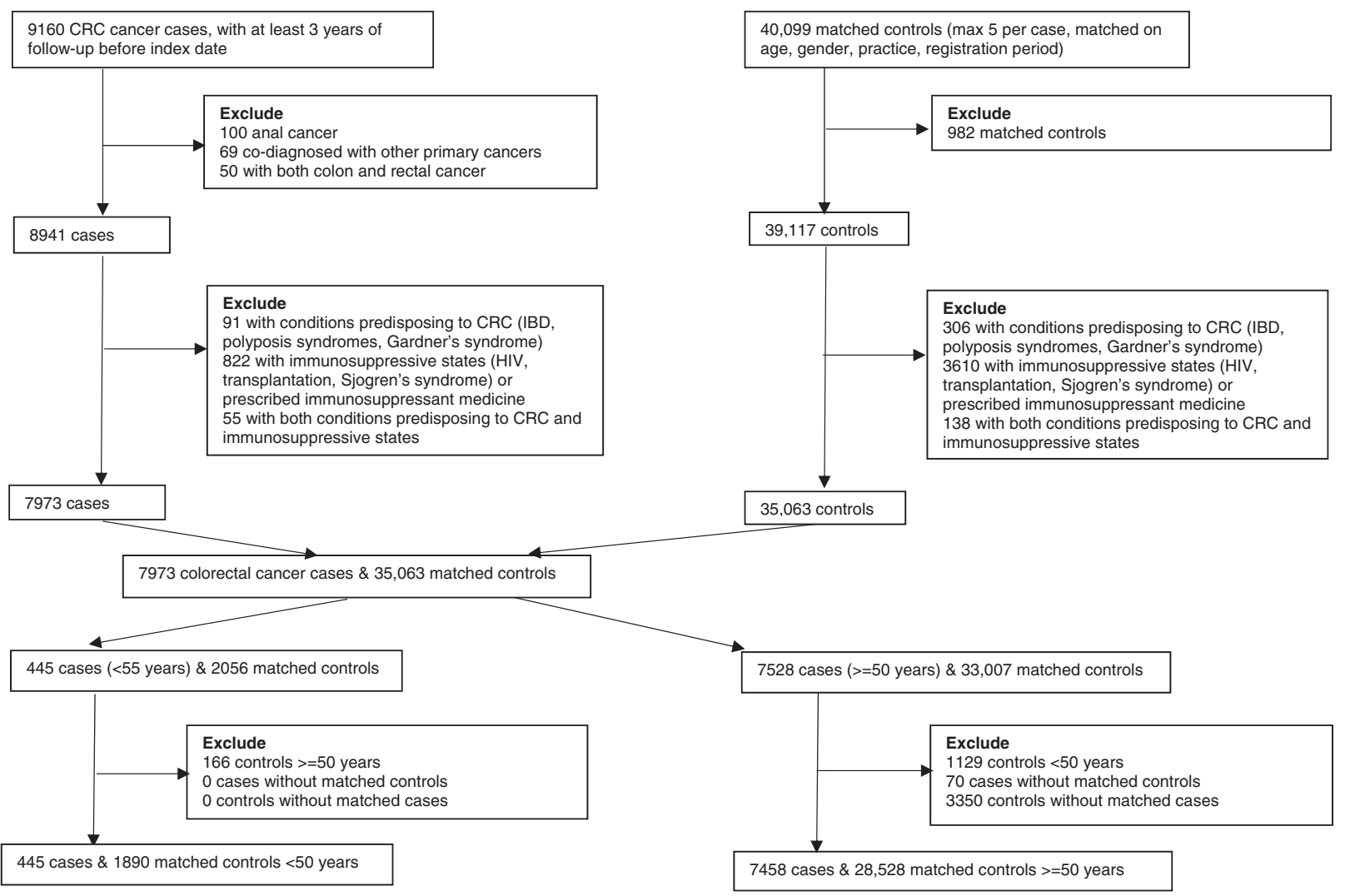

Fig. 1 Data extraction flow chart. CRC: colorectal cancer; IBD: inflammatory bowel disease.

Several single-centred studies [4, 24-32] and two recent systematic reviews and meta-analyses $[7,8]$ found an association between oral antibiotics CRC risk. However, these studies are contradictory; whether risk varies with tumour location or with use of anti-aerobic or antianaerobic agents (i.e. antibiotics active against bacteria requiring oxygen, or lack of oxygen, to survive) or both, remains uncertain. To our knowledge, no study before has investigated antibiotic usage in the early-onset CRC population; participant mean age is 69-72 years in all recorded studies [4, 24-32].

This study seeks to determine the association between antibiotic use and early-onset CRC, and whether any risk may differ within the colorectal continuum, or by antibiotic spectrum of activity.

\section{MATERIALS AND METHODS}

\section{Data source}

Study data were obtained from the population-based Primary Care Clinical Information Unit Research (PCCIUR) database [33], comprising over two million patients registered at 393 general practices across Scotland between 1993 and 2011. PCCIUR contains up to 20 years of demographic, clinical and diagnostic information and has been widely used in epidemiological research [34-37].

\section{Study design}

A case-control study was conducted using PCCIUR data. Cases were patients with a new diagnosis of primary CRC (Read codes B13, B14, see Supplementary Material Table S1) between 1999 and 2011. Cases were excluded if they had a previous cancer, excluding non-melanoma skin cancer, or were diagnosed with other primary cancers on the date of diagnosis due to uncertainty about the primary cancer and the potential for coding errors. Cases of anal cancer were excluded as they are squamous cell cancers and associated with HPV infection. Patients with diagnosed conditions predisposing to CRC (e.g. inflammatory bowel disease, Peutz-Jeghers syndrome, polyposis syndromes) were excluded as our study was limited to sporadic CRC. Patients with diagnosed immunosuppressive states (e.g. Sjogren's syndrome, HIV infection, transplantation) and those in receipt of immunosuppressive medicines during the exposure period (see definition below) were also excluded.

All available controls (alive, registered with a GP and free from cancer (excepting non-melanoma skin cancer)) were identified for each case matching on practice, year of birth ( \pm 5 years), gender and year of registration (in categories). Up to five controls for each case were randomly selected from those available, without replacement. The index date within each matched set was defined as the diagnosis date of CRC in the case. Both cases and controls needed at least three years of follow-up data and remained registered with the same general practice over the follow-up period. Two strata were constructed for comparative purposes, a younger strata (cases plus matched controls $<50$ years) and an older strata (cases plus matched controls $\geq 50$ years) $[5,6,38]$. Data extraction are depicted in Fig. 1.

Within each matched set, the exposure period, i.e. the period of time over which medicine use was determined, started on either 1 January 1993 (as prescriptions before this time were unlikely to be recorded electronically), or the most recent GP registration date if this occurred after January 1993. This ensured all members within each matched set had the same exposure period. The exposure period ended 1 year before the index date, to reduce the risk of reverse causality and exclude medications unlikely to have had sufficient time to cause cancer [39]. Rectal or rectosigmoid junction tumours were classified as rectal cancer, otherwise tumours were classified as colon cancer.

\section{Classification and definition of antibiotic exposure}

Prescriptions for oral antibiotics were extracted from PCCIUR. These were classified by drug class and by presence or absence of anti-anaerobic effects to provide insight into bacterial populations potentially associated with CRC [4]. Medicines studied are listed in the Supplementary Material Table S2.

For each antibiotic prescription, the duration of treatment (in days) was identified from prescribing records. Where this was not recorded $(n=536$ (1.1\%) of all antibiotic prescriptions), treatment duration was estimated according to standard dosing for each antibiotic. Total exposure in days of all antibiotic classes was calculated for each patient and categorised as 0 days, $1-15$ days, $16-60$ days, $>60$ days $[40,41]$. Analyses were also 
conducted using cumulative duration of anti-anaerobic or non-antianaerobic antibiotic treatment. For these analyses only primary clinical therapeutic effect(s) of each medicine were considered; other antimicrobial activity is often less pronounced without major effects on aerobic or anaerobic populations [42].

\section{Covariates}

The following comorbidities, based upon published Read codes for the Charlson Comorbidity Index (CCl) [43], were identified prior to or during the exposure period: diabetes, myocardial infarction, coronary heart disease, heart failure, peripheral vascular disease, dementia, cerebrovascular disease, chronic obstructive pulmonary disease, osteoporosis, renal disease, liver disease and hemiplegia/paraplegia. Additional comorbidities, relevant to CRC (i.e. gallstones, acromegaly), were also identified. We also adjusted for use of low dose aspirin and non-steroidal anti-inflammatory drugs (NSAIDs), as these may reduce risk of CRC $[44,45]$. Smoking status (non-smoker, current smoker, former smoker) [46] and alcohol consumption (non-drinker, light or moderate drinker, heavy drinker) [47] were determined from the most recent smoking or alcohol record prior to or during the exposure period.

\section{Statistical analysis}

Descriptive statistics summarised cases and controls. For each cohort, conditional logistic regression was used to calculate odds ratios (OR) and 95\% confidence intervals $(\mathrm{Cl})$ for associations between each exposure and CRC, with adjustment for comorbidities. The matched design accounted for age ( \pm 5 years), GP practice, gender and year of registration. All analyses were adjusted for age in years, as participants were matched in age bands rather than by calendar year. Interaction tests to determined whether antibiotic exposure effects varied by strata. To test for trend in risk of colorectal cancer across different categories of treatment length, the duration of antibiotic exposure was treated as a continuous rather than a categorical variable. Associations between individual classes of antibiotics and colon/rectal cancer are reported as supplementary analyses due to low prescribing levels of individual classes among patients under 50 years and the increased risk of type 1 errors due to multiple testing.

\section{Subgroup analyses}

Analyses were repeated for matched sets where location of cases' colon tumour was explicitly recorded in the diagnostic readcodes, namely proximal colon (malignant neoplasms of hepatic flexure, transverse colon, caecum, appendix or ascending colon) and distal colon (malignant neoplasms of the descending colon, sigmoid colon or splenic flexure of colon). The primary analyses were repeated using the subsample of patients with recorded body mass index (BMI).

\section{Sensitivity analyses}

Sensitivity analyses were undertaken as follows: (1) period of time before index date during which prescriptions were not counted was increased from 1 to 2 years to reduce potential for reverse causation; (2) threshold used to distinguish between younger and older patients was lowered from 50 years to 45 years; (3) threshold used to distinguish between younger and older patients was increased from 50 years to 55 years; (4) adjustments were made for comorbidities, smoking and alcohol use for the 23,702 patients $(61.2 \%)$ where both lifestyle factors had been recorded in the patient's clinical records. The latter analysis was also repeated using multiple imputation with chained equations (MICE) techniques to impute smoking and alcohol status. This is a simulation-based method appropriate for handling missing data assuming that such values are missing at random. Ordered logit models were used with age, gender, deprivation within the GP practice locality, and comorbidities for the imputations, stratified by case-control status and using 25 imputations [48].

\section{RESULTS}

\section{Descriptive statistics: cases and controls}

Seven thousands nine hundred and three CRC cancer cases and 30,418 matched controls were identified. Five thousands three hundred fifty six cases $(67.8 \%)$ had at least four matched controls. There were 5281 colon cancer cases and 2662 rectal cancer cases. Median (inter-quartile range (IQR)) age at diagnosis in the younger and older strata was $45[41,47]$ years and 71 years $(63,78)$, respectively. The exposure period, matched in cases and controls, was slightly shorter for patients $<50$ years (median (IQR) 6.9 (4.8, 9.2) years) than patients $\geq 50$ years (median (IQR) $7.9(5.3,10.8)$ years). Approximately $55 \%$ of patients were male in each agegroup.

Characteristics of cases and controls are listed in Table 1. A full set of descriptive statistics of cases and controls by each tumour location is provided as Supplementary Material Table S3.

\section{Descriptive statistics: antibiotic medication}

$44.9 \%(17,206)$ of patients were prescribed antibiotics during the exposure period. The proportion of CRC cases prescribed antibiotics was larger than the proportion of controls prescribed antibiotics in both the $<50$ strata (cases: $47.2 \%$ (210) v controls: $40.1 \%(757)$ ) and the $\geq 50$ years strata (cases: $46.8 \%$ (3496) $v$ controls: $44.7 \%(12,743))$. Most commonly prescribed antibiotics were penicillins $(52.8 \%(25,473)$ of all antibiotic prescriptions). The proportion of cases prescribed each class of antibiotic was usually higher than the proportion of controls in both age-groups for both colon and rectal cancer.

Antibiotics with anti-anaerobic effects were more commonly prescribed than antibiotics without anti-anaerobic effect $(52.7 \%$ $(25,440) \vee 47.3 \%(22,851))$. Prescribing of both anti-anaerobic antibiotics and non-anti-anaerobic antibiotics was higher among cancer cases than controls in both age-groups and cancer sites. Descriptive statistics for class of antibiotic medication by agegroup and tumour location are given in Table 2.

\section{Associations between use of antibiotics and CRC}

Use of antibiotics was associated with increased risk of colon cancer in both age-groups ( $<50$ years: adjusted Odds Ratio $\left(\mathrm{OR}_{\mathrm{adj}}\right)$ $1.49(95 \% \mathrm{Cl} 1.07,2.07), p=0.018 ; \geq 50$ years: $\mathrm{OR}_{\mathrm{adj}} 1.09(95 \% \mathrm{Cl}$ $1.01,1.18), p=0.029)$ ) (Table 3). Although this effect was greater among patients $<50$ years compared to those $\geq 50$ years, the difference was not significant (interaction test: $p=0.071$ ). There was no apparent exposure-response relationship between antibiotic use and colon cancer risk for either age-groups ( $<50$ years: $P$-trend $p=0.177 ; \geq 50$ years: $P$-trend $p=0.082$ ). Antibiotics use was not significantly associated with increased rectal cancer risk in either age-group ( $<50$ years: $\mathrm{OR}_{\mathrm{adj}} 1.17$ (95\% Cl 0.75, 1.84), $p=$ 0.493 ; $\geq 50$ years: $\left.\mathrm{OR}_{\mathrm{adj}} 1.07(95 \% \mathrm{Cl} 0.96,1.19), p=0.238\right)$ ).

Analyses of antibiotic prescribing by treatment duration and CRC location are depicted graphically in Forest Plots (Fig. 2) and listed in Supplementary Material Table S4.

There was no evidence at the $5 \%$ statistical significance level of any differences between the the two age-groups in associations between classes of antibiotic use and the risk of colon or rectal cancer (Supplementary Material Table S5).

\section{Associations between anti-anaerobic effects and CRC}

Although not significant, use of anti-anaerobic antibiotics was associated with increased risk of colon cancer in both strata $(<50$ years: $\mathrm{OR}_{\mathrm{adj}} 1.34(95 \% \mathrm{Cl} 0.97,1.86), p=0.078 ; \geq 50$ years: $\mathrm{OR}_{\mathrm{adj}}$ $1.08(95 \% \mathrm{Cl} 1.00,1.17), p=0.054)$ (Table 3). However, these effects did not differ significantly from each other (interaction test: $p=0 \cdot 204)$ and there was no apparent exposure-response relationship in either age-group ( $<50$ years: $P$-trend $p=0.386 ; \geq 50$ years: $P$-trend $p=0.105$ ). Antibiotic use was not significantly associated with increased risk of rectal cancer in either age-group ( $<50$ years: $\mathrm{OR}_{\mathrm{adj}} 1.11(95 \% \mathrm{Cl} 0.70,1.76), p=0.646 ; \geq 50$ years: $\mathrm{OR}_{\text {adj }} 1.00(95 \%$ $\mathrm{Cl} 0.89,1.11), p=0.974)$ ).

\section{Associations between non-anti-anaerobic effects and CRC} There was some evidence that use of antibiotics without antianaerobic effects was associated with increased risk among patients $<50$ years of both colon cancer $\left(\mathrm{OR}_{\mathrm{adj}} 1.37(95 \% \mathrm{Cl} 0.97\right.$, $1.93), p=0.075)$ and rectal cancer $\left(\mathrm{OR}_{\mathrm{adj}} 1.70(95 \% \mathrm{Cl} 1.06,2.74)\right.$, $p=0.029$ ), but not among patients $\geq 50$ years (colon cancer: $\mathrm{OR}_{\mathrm{adj}}$ 
Table 1. Characteristics of cases and controls.

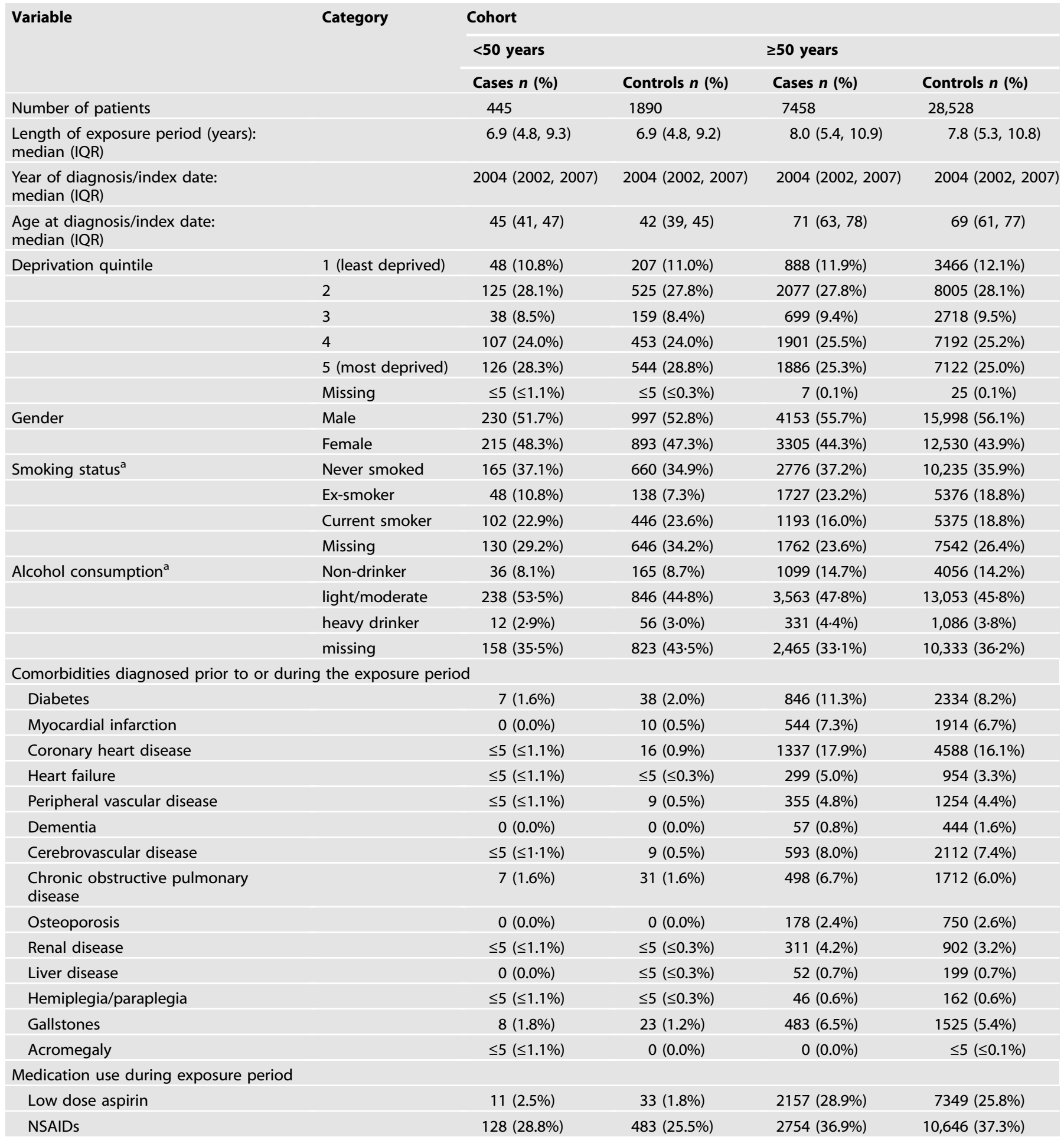

IQR inter-quartile range, NSAIDs non-steroidal anti-inflammatory drugs.

${ }^{\mathrm{a}}$ Most recent record in patient's clinical history prior to 1-year lag.

$1.03(95 \% \mathrm{Cl} 0.95,1.11), p=0.500$; rectal cancer: $\mathrm{OR}_{\mathrm{adj}} 1.05(95 \%$ $\mathrm{Cl} 0.93,1.18$ ), $p=0.436$ ) (Table 3). However, these effects neither vary between age-groups (interaction test: colon cancer $p=0.151$, rectal cancer $p=0.888$ ), nor was there an exposure-response relationship between use of antibiotics without anti-anaerobic effects and either colon or rectal cancer risk in either age-groups.

\section{Subgroup analyses}

There were $687(13.0 \%)$ colon cancer cases classified as proximal colon and 551 (10.4\%) classified as distal colon. Use of antibiotics, antibiotics with anti-anaerobic effects and antibiotics without antianaerobic effects was associated with increased risk of proximal colon cancer among $<50 \mathrm{~s}$ (any antibiotic $\mathrm{OR}_{\text {adj }} 3.78(95 \% \mathrm{Cl} 1.60$, 
Table 2. Antibiotic use, by class, in cases and controls.

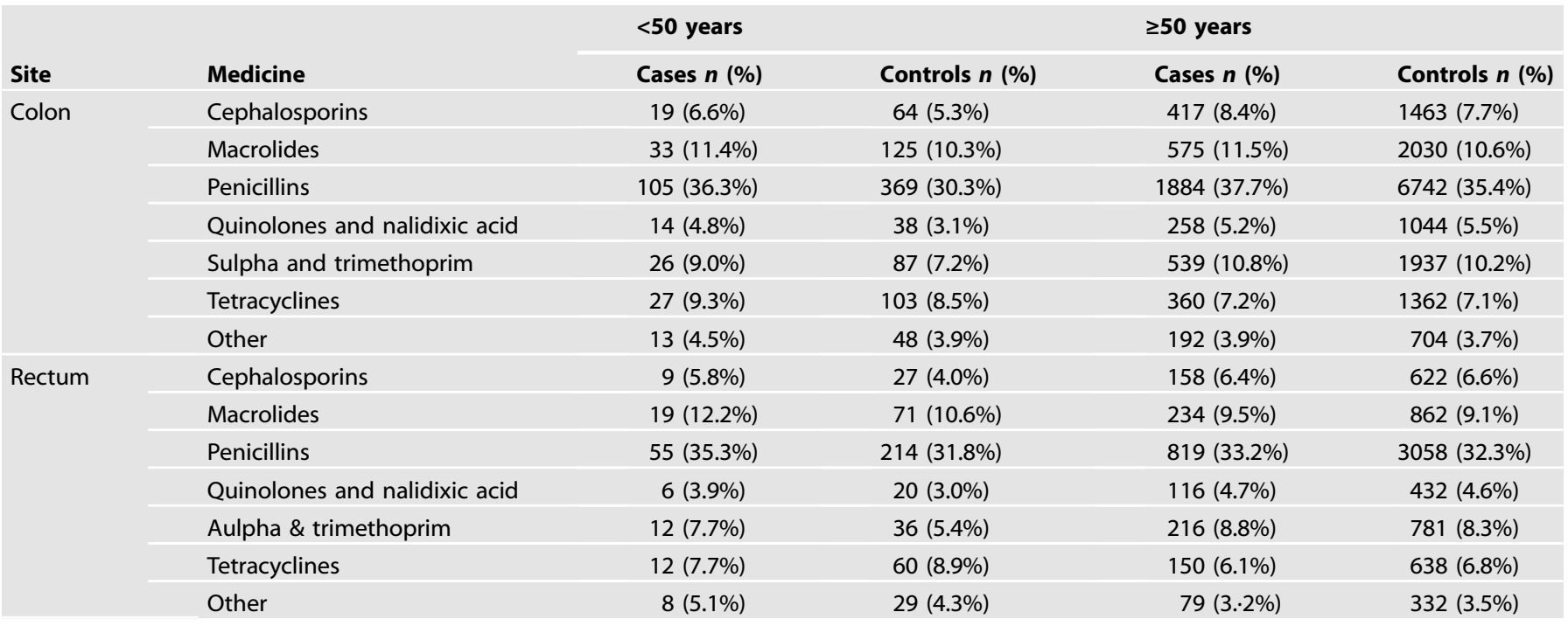

8.92), $p=0.002$; anti-anaerobic $\mathrm{OR}_{\text {adj }} 2.17(95 \% \mathrm{Cl} 1.00,4.68), p=$ 0.049 ; non-anti-anaerobic $\left.\mathrm{OR}_{\text {adj }} 2.86(95 \% \mathrm{Cl} 1.21,6.73), p=0.016\right)$. It appeared effects associated with antibiotic use and antianaerobic antibiotics differed between the two age-groups (interaction test: any antibiotic $p=0.001$; anti-anaerobic $p=$ 0.034). A positive exposure-response relationship was also observed between antibiotic prescribing and risk of proximal colon cancer among the younger patients $(P$-trend $=0.004)$ ). Results for both subgroup analyses are listed in Table 3 and Supplementary Material Table S6.

One-third of all patients included in our analyses $(n=12,657)$ (33.0\%) had their BMI reported, and these patients were on average slightly overweight (median (IQR) 26.7 (23.9,29.9)). Patients with recorded BMI were less likely to be non-smokers or non-drinkers, and have higher reported levels of comorbidities and prescribed medication, than patients where BMI was missing (Supplementary Material Table S7). Adjusting for BMI in addition to comorbidities and medicine use increased the magnitude of the association between any antibiotic use and early-onset colon cancer risk ( $\left.\mathrm{OR}_{\mathrm{adj}} 1.98(95 \% \mathrm{Cl} 0.82,4.81), p=0.130\right)$, although this association did not differ significantly between that reported with the older age-group $\left(\mathrm{OR}_{\mathrm{adj}} 1.01(95 \% \mathrm{Cl} 0.87,1.16), p=0.920\right)$ (interaction test: $p=0.139$ ). Full details of these subgroup analyses are reported in Supplementary Material Tables S8 and S9.

\section{Sensitivity analyses}

Results from sensitivity analyses are listed in Table 4. Increasing lag-time from one year to 2 years or additionally adjusting for alcohol and smoking had no substantive impact on reported associations between antibiotic use and CRC risk.

\section{DISCUSSION}

In this large population-based case-control study of early-onset CRC cases and later-onset CRC cases, antibiotic consumption was associated with colon cancer pathogenesis across all age-groups.

Results from a systematic review and meta-analysis of 10 highquality observational studies found antibiotic use increased CRC risk (effect size (ES) $1.17(95 \% \mathrm{Cl} 1.05,1.30)$ ), but associations differed with tumour location and antibiotic classes [7]. Analysis of colon cancer cases alone showed no significant association (ES $1.06(95 \% \mathrm{Cl} 0.89,1.26))$. However, there was high heterogeneity between studies $\left(I^{2}=95.7 \%\right.$ and $83.5 \%$, respectively), which-if our findings are true-may partly reflect varying and older age-groups included in those studies. Other than colon and rectal cancer, the meta-analysis did not explore the influence of antibiotics on tumour locations further-such as association with proximal colon cancer. Another systematic review and metaanalysis suggested a weak association may exist between antibiotic consumption and risk of CRC [8]. However, definitive conclusions cannot be made given the small number of studies included, a lack of control for confounding and high heterogeneity. Furthermore, none of the studies analysed antibiotic exposure during childhood and adolescence, a time when individuals are most vulnerable to gut dysbiosis [8].

Although we found limited associations between antibiotic usage and rectal cancer across all age-groups, non-anti-anaerobic (i.e. exclusively anti-aerobic) antibiotics among the young agegroup only were observed to increase risk of colon, rectal, proximal and distal colon cancer more than anti-anaerobic antibiotics. This conflicts with a case-control study of participants aged 40-70 years, which found anti-aerobic antibiotics to protect against distal colon and rectal cancer, whereas anti-anaerobic antibiotics increased risk of cancer-particularly in the proximal colon [4]. A further study [28] found both anti-aerobic and antianaerobic agents were associated with CRC, whereas another found just anti-anaerobic antibiotics increased risk [27]. However, sample sizes among our early-onset CRC cohort were small, especially when stratified into non-anti-anaerobic antibiotics and length of treatment. Furthermore, it may be clinically irrelevant whether anti-anaerobic or anti-aerobic antibiotics have a role in tumour formation, as most antibiotic drugs have dual antianaerobic and anti-aerobic activity.

Coinciding with existing studies, a very strong association was observed between antibiotic consumption and proximal colon cancer [4, 40,49]; however, this was only observed in the earlyonset CRC subgroup analysis, which had a small sample size of just 50 cases. With a greater microbial diversity and concentration of short-chain fatty acids, the proximal colon is more vulnerable to antibiotic exposure than the distal colon and rectum $[49,50]$. Dysbiosis results in altered bacterial activity, fermentation and therefore colonic $\mathrm{pH}$, in addition to interruption of protective colonic mucus leading to direct contact between the biofilm and epithelial cells, leading to chronic inflammation [12, 50, 51]. In all cohorts, there was limited evidence of a positive exposureresponse relationship between cumulative antibiotic use and risk of CRC, with the exception of proximal colon cancer in the younger cohort. This supports previous literature suggesting risk 


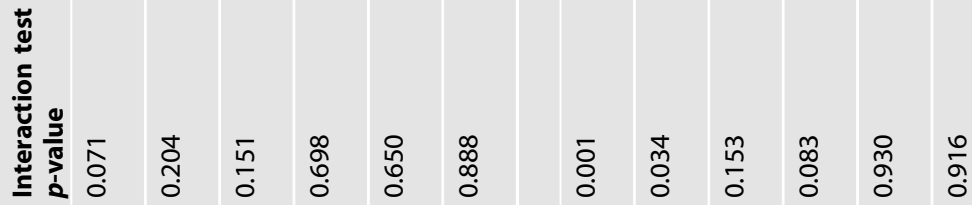

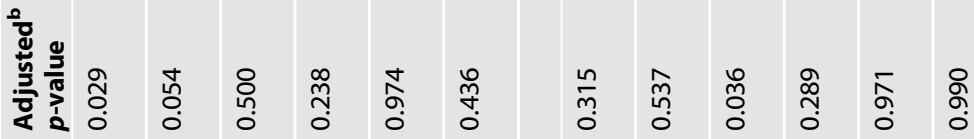

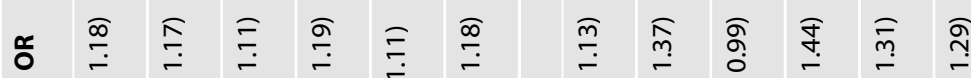

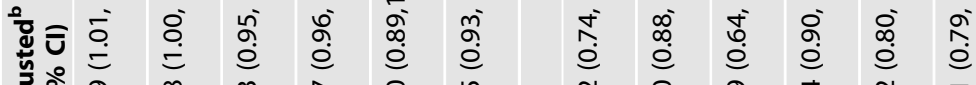

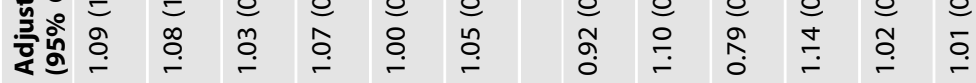

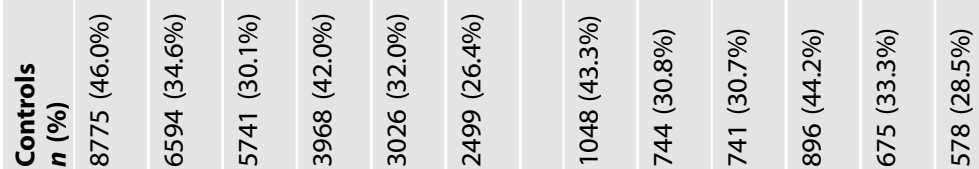

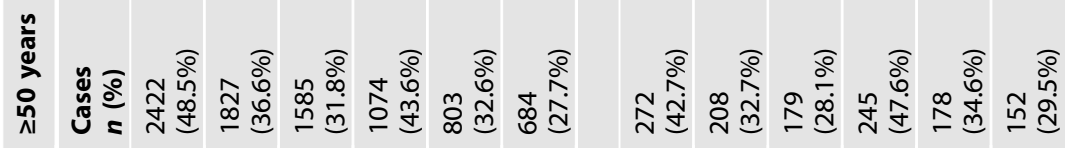

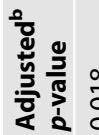

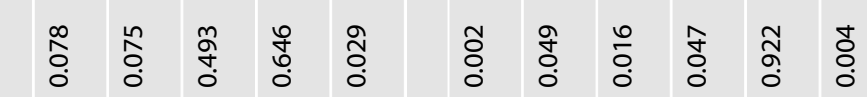

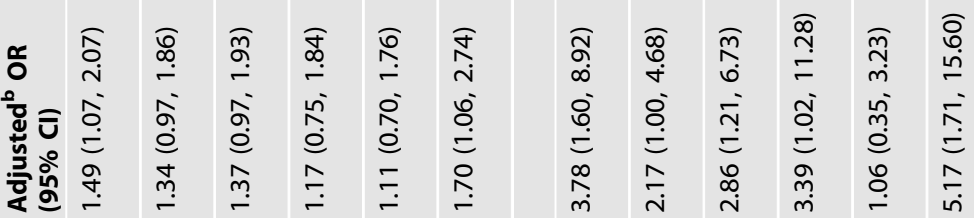

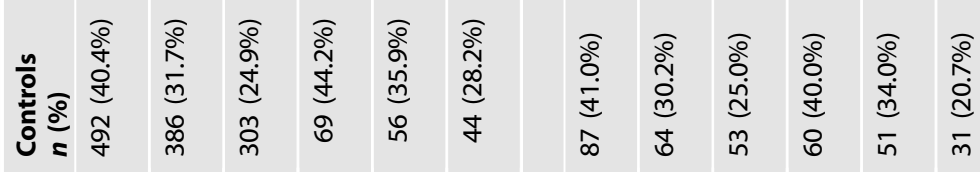

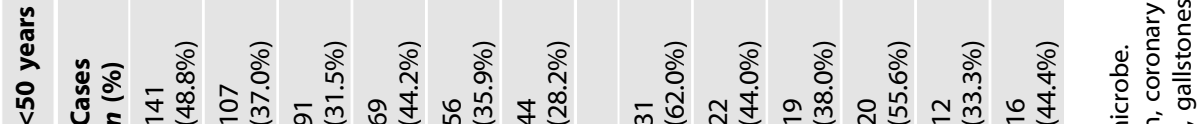

认̂

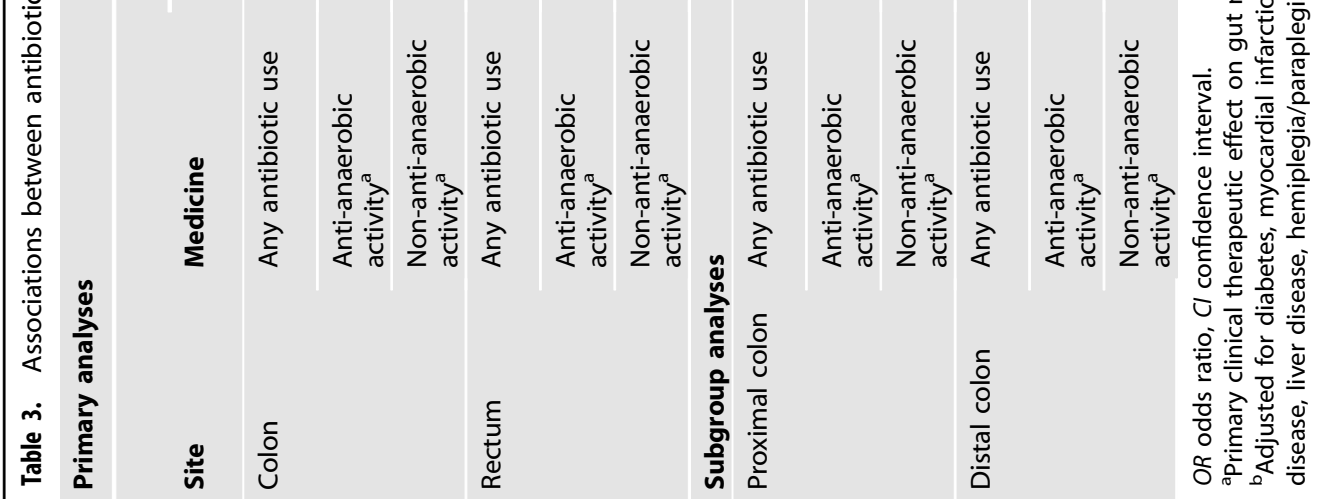


Colon $<50$ years

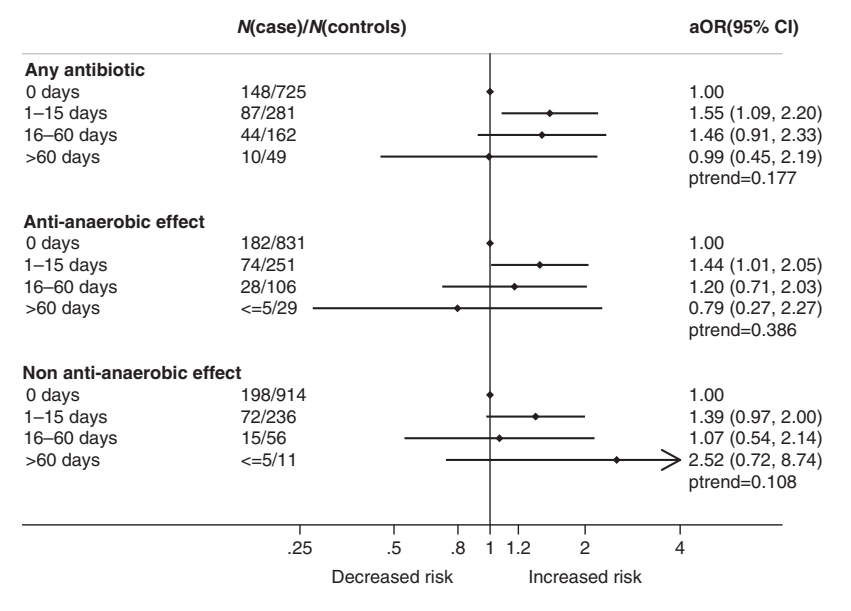

Rectum $<50$ years

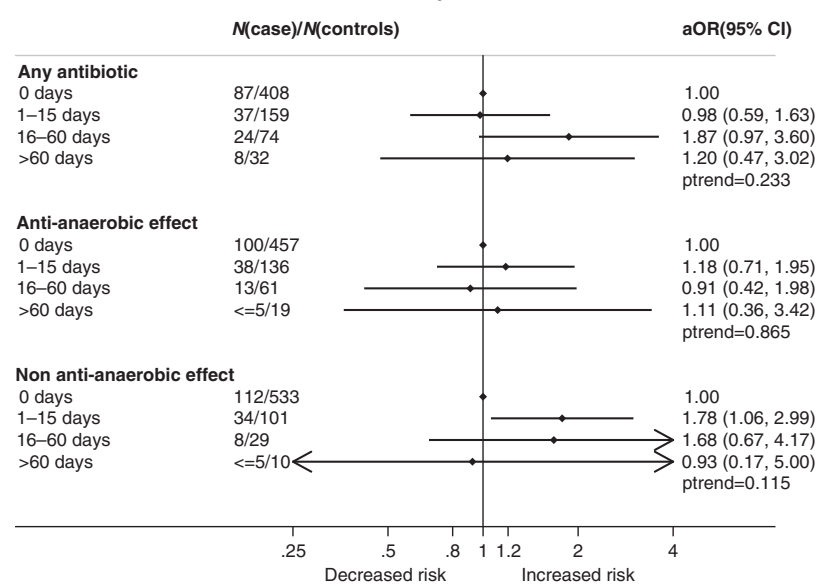

Colon $>=50$ years

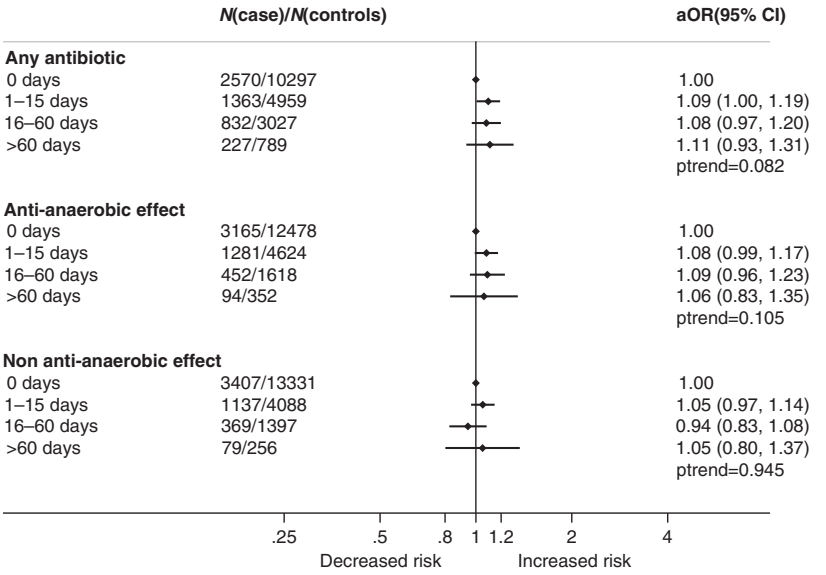

Rectum $>=50$ years

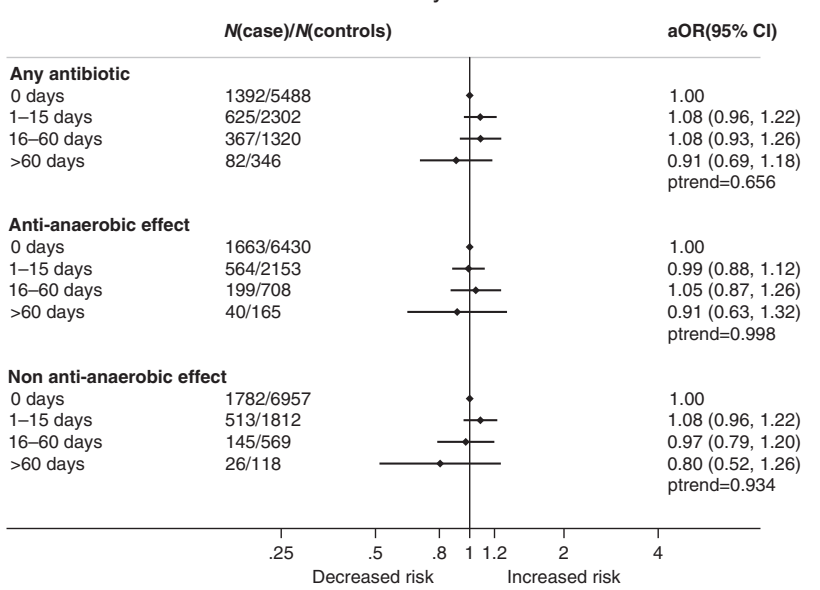

Fig. 2 Forest plots for associations between antibiotic use and risk of colorectal cancer. aOR: adjusted Odds Ratio; N: Number analyses adjusted for diabetes, myocardial infarction, coronary heart disease, heart failure, peripheral vascular disease, dementia, cerebrovascular disease, chronic obstructive pulmonary disease, osteoporosis, renal disease, liver disease, hemiplegia/paraplegia, gallstones, acromegaly, low dose aspirin and NSAIDs

increases after minimal antibiotic use [4], with risk not necessarily increasing with prolonged antibiotic exposure [7, 49].

Whether the observed relationship between antibiotics and CRC is causal remains uncertain. CRC is a complex, "heterogenous" disease with many underlying molecular mechanisms and risk factors [11]. Compared to later-onset disease, early-onset CRC has been described as a remarkably distinctive subset of disease $[5,6,11]$. Therefore, to compare our findings with previous studies, which have not considered the impact of age on CRC in addition to antibiotic exposure, may be inappropriate. If we were to disregard this fact, according to the Bradford Hill criteria [52], it is likely that a causal relationship may exist. Our findings indicate a strong association between antibiotic use and CRC, particularly with colon cancer. Our study is somewhat consistent with the literature, suggesting a relationship does exist-even if effect sizes vary. There is evidence of temporality in other studies [29], although we found no evidence of a biological gradient except in the case of early-onset proximal colon cancer. A causal relationship is plausible and coherent, and we can draw parallels with other commonly accepted phenomena-such as antibioticinduced microbiome changes increasing risk of obesity, autoimmune disease and metabolic disorders [53-55], and the anticancer effects of a healthy microbiome [21]. However, the relationship is not particularly specific; with around 67 million courses of antibiotics prescribed each year in the USA to children aged less than 19 [18], exposure to antibiotics among the young is incredibly common. It is therefore hard to judge how many of these exposed individuals will potentially be diagnosed with earlyonset CRC - a relatively rare disease outcome [9].

In our study, we observed more participants with CRC had rectal cancer in the younger rather than the older cohort. A study investigating USA early-onset CRC trends suggest rectal cancer incidence in the young is increasing more rapidly than colon cancer; by 2030, they predict incidence of colon and rectal cancer will increase by $90 \%$ and $124 \%$ among patients aged $20-34$ years [56]. A possible association may exist between sexually transmitted infections and early-onset rectal cancer; [49] Chlamydia infections have malignant potential and secondary rectal infection is common [57, 58]. A review of clinical and molecular features of early-onset CRC suggests distal colon and rectal cancer are predominantly features of early-onset CRC, whereas proximal cancers tend to feature in later-onset disease [11]. Despite this, it is likely that sporadic early and later-onset CRC are otherwise indistinguishable in terms of genomics and biology [12]. The embryological origins of the proximal colon (midgut) and distal colon and rectum (hindgut) are different, as are biological features of cancers arising in these areas; proximal have more microsatellite instability, and distal more chromosomal instability [59]. Together with differences in the luminal contents and microbiome, it is biologically plausible that antibiotic consumption 


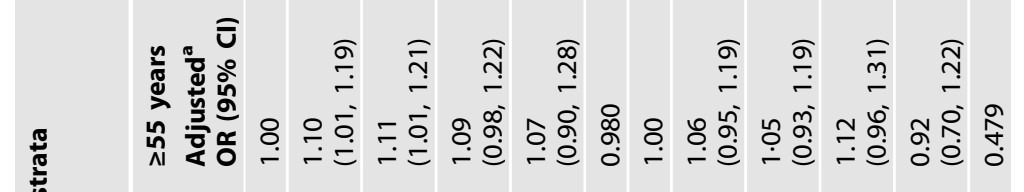

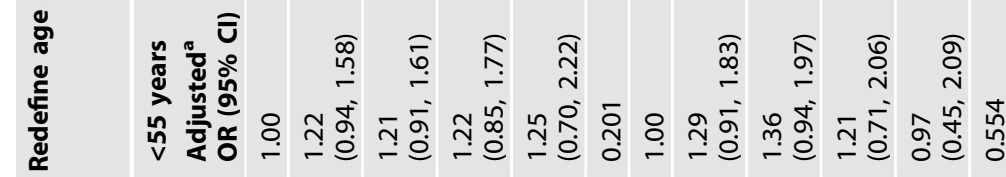

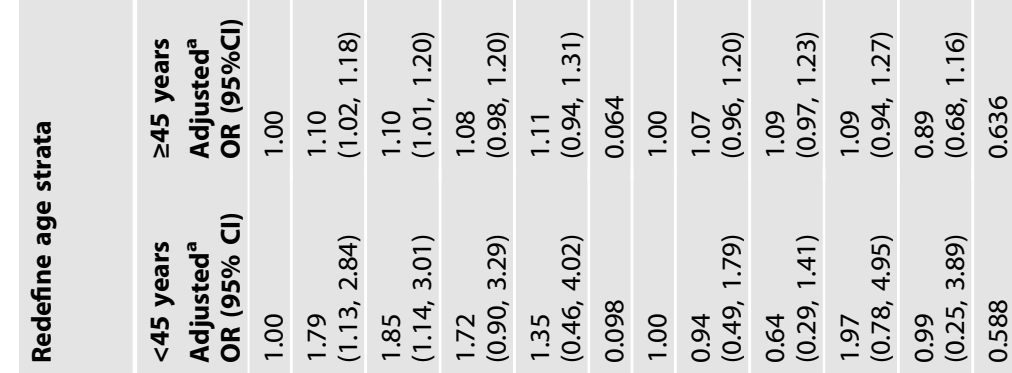

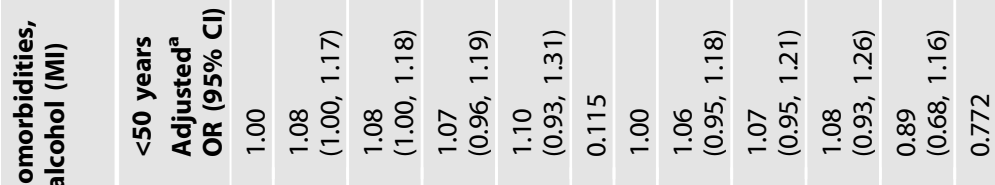

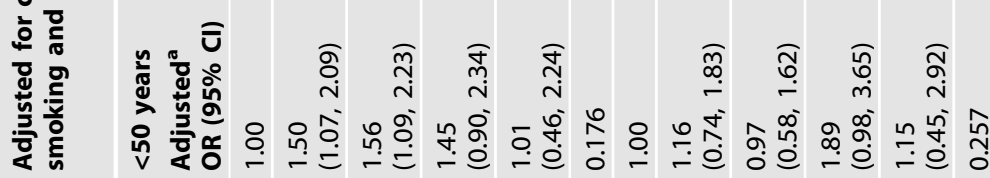

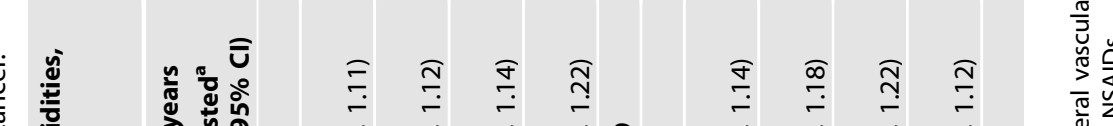

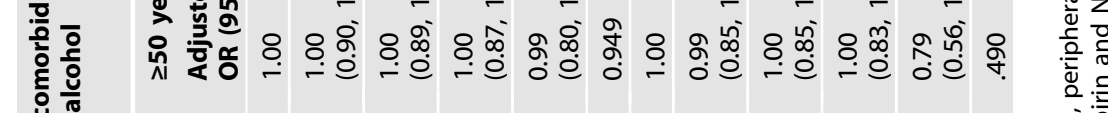

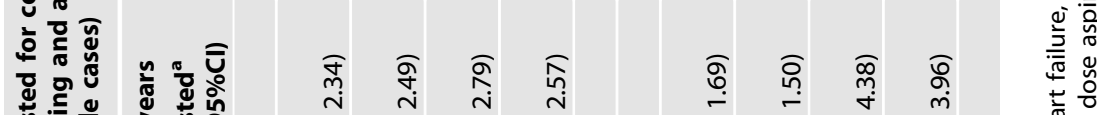

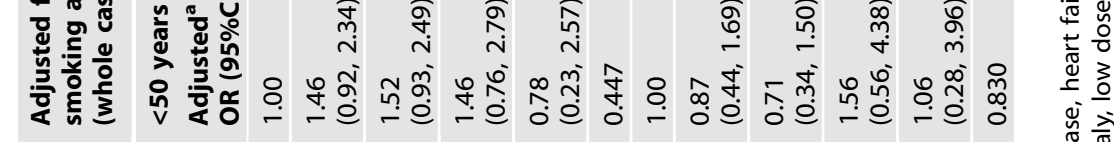

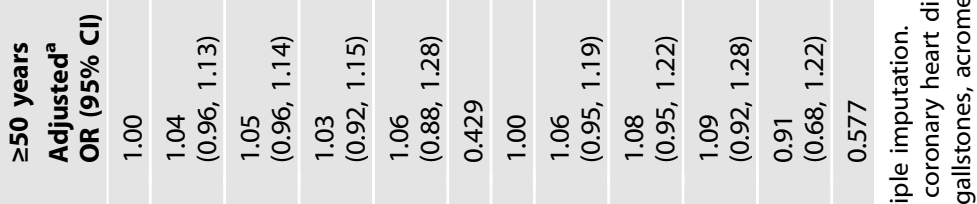

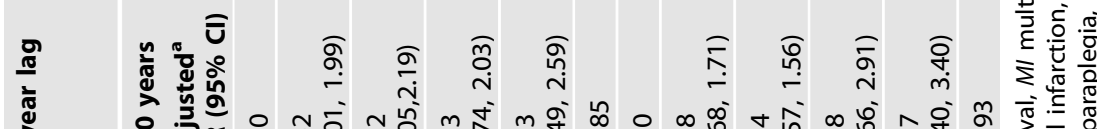
ì

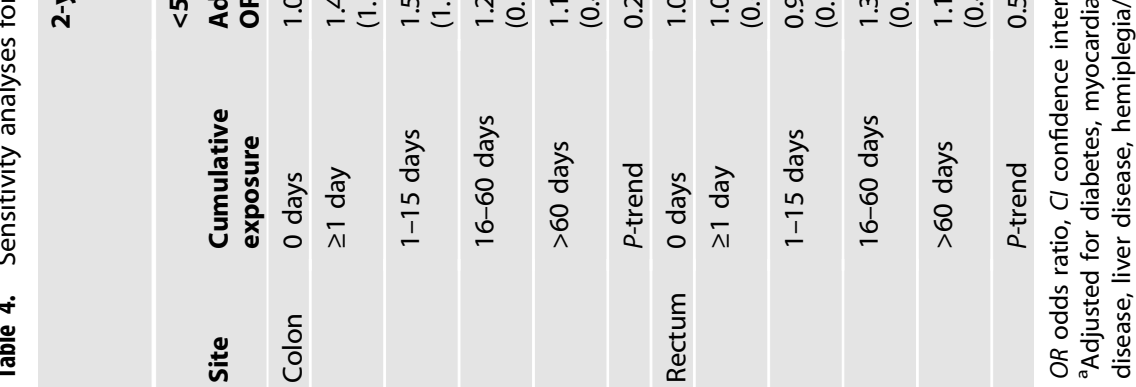


could influence the development of colonic and rectal cancer differentially by location.

There are multiple elements likely to be driving the increase in early-onset CRC including dietary factors-such as increased consumption of red and processed meat, monosodium glutamate, titanium dioxide and high-fructose corn syrup; obesity; stress; reduced exercise; and antibiotic consumption [5]. There is a scarcity of studies investigating early-life exposures and adultonset cancers, although the aforementioned factors at interplay are known to have adverse effects on the microbiome. In addition, lifestyle changes occurring since the 1950 s correlate with the increased rates of CRC, especially among the young [60]. Evidence of possible carcinogenic effects of antibiotics are limited [61], yet some antibiotics commonly up-regulate cyclooxygenase-2-a mechanism proven to promote development of CRC $[62,63]$. Furthermore, it is the antibiotic-induced microbiome changes which disrupt immunostimulatory bacteria and give rise to pathogenic colonisation which is likely to be carcinogenic, rather than the actual medications themselves [21, 22].

This study has several strengths. PCCIUR is nationally representative, covering at least $15 \%$ of the Scottish general practice population [35]. Comprehensive linking of practice data to Scottish Cancer Registry data provides high coverage of CRC cases (given the relative rarity of early-onset $\mathrm{CRC}$ ) and a relatively long exposure period. Thorough cleaning and validation of the data has minimised loss of prescription items due to transcription errors. This allowed accurate calculation of cumulative antibiotic exposure in primary care by class or spectrum of activity. In the UK, antibiotics can only be obtained with a medical prescription, and over-the-counter purchases are not possible. Although we could not access secondary care prescriptions, antibiotics commenced in hospital with long-term intent will appear in subsequent GP prescribing records. In our analyses we make a distinction between patients with early-onset CRC and later-onset CRC, and used sensitivity analysis to determine whether results changed when the age threshold used to define the two strata was altered.

Inevitably, this study also has its limitations. Given CRC in those aged less than 50 years is relatively rare, we had just 445 cases. Our sample size decreased further when we explored antibiotic spectrum of activity and specific tumour locations, and inevitably some analyses among patients under 50 years will be underpowered. Individuals with immunosuppressing conditions or diagnosed genetic predispositions to CRC were excluded; these make up a significant proportion of early-onset CRC patients, and the impact of antibiotic therapy in these groups will therefore not be measurable. Although we managed to exclude participants with genetic predispositions to CRC, the PCCIUR dataset does not provide information on a participants' family history or dietary habits (BMI was only reported for $\sim 33 \%$ of our sample). These both have a significant influence on CRC risk, for example the increased risk associated with obesity and CRC is well-known [64]. However the low numbers of cases among patients under 50 years where BMI was reported means that we cannot comment substantively on the nature of any association of BMI with CRC risk on the basis of our analyses. Long-term effects of exposure to antibiotics in childhood, when the gut microbiome is developing and potentially more vulnerable, are yet to be evaluated in terms of cancer risk and may be of clinical importance [65]. Unfortunately, lack of prescribing data in PCCIUR prior to 1993 means we are not able to explore whether initial age of exposure to antibiotics is associated with CRC risk.

Our dataset is suspectable to various biases associated with observational data, such as differential recall and reverse causation. The latter may be observed if patients presenting with stomach pain are initially diagnosed with gastrointestinal infection and prescribed antibiotics. Although we adjusted for use of medicines, smoking and alcohol use, residual confounding may be present (e.g. NSAID strength/duration of prescribing, units of alcohol consumed, number of pack years for smokers). There may be unmeasured confounding in the main analyses due to the inability to adjust for other relevant confounders not reported comprehensively in our data (e.g. BMI). Discrepencies in tumour location data may exist, with cases recorded as 'colon' rather than the sub-site within the colon. In addition, some patient groups will be missing from primary care records and cannot be accounted for, such as the homeless, private patients and prisoners. There will also be variability between prescribers regarding completeness of comorbidity recording. Data not captured by PCCIUR includes most secondary care prescriptions, private healthcare records, antibiotic prescriptions before 1993 (as these will not have been recorded electronically), and prescription adherence. These could be highly relevant to the study. Finally we cannot guarantee that patients adhered to their prescription medication, which seems likely to dilute any real associations, although studies suggest adherence to antibiotic therapy is high [66].

Our findings, showing no significant difference between the associations with early and later-onset disease, supporting recent evidence suggesting there are more similarities than differences between early and later-onset disease [12]. Therefore future studies to further elucidate any role of antibiotics in CRC genesis should be inclusive of all age-groups.

In conclusion, our findings suggest antibiotic exposure is associated with CRC genesis across all age-groups. It is possible that antibiotic exposure may be contributing to cases of CRC, potentially more so among the young. Our study raises the question whether antibiotic usage history should be included in the standardised proformas for referral from primary to secondary care. Further studies to confirm our findings and evaluate longterm effects of antibiotics on gut health are required, and increased awareness of the potential harms associated with antibiotic usage among clinicians and members of the public is necessary.

\section{DATA AVAILABILITY}

The datasets analysed in this study are not publicly available and were used under license. Requests for PCCIUR data should be directed in the first instance to Katie Wilde (Research Manager), email: k.wilde@abdn.ac.uk.

\section{CODE AVAILABILITY}

Standard statistical techniques were used to analyse the data, for which code can be obtained via the corresponding author. All statistical analyses were undertaken using Stata 15 [67]. Results were significant if they referred to statistical significance on a two-sided design-based test evaluated at the $5 \%$ level.

\section{REFERENCES}

1. Vuik FER, Nieuwenburg SAV, Bardou M, Lansdorp-vogelaar I, Dinis-ribeiro $M$, Bento $\mathrm{MJ}$, et al. Increasing incidence of colorectal cancer in young adults in Europe over the last 25 years. Gut. 2019;68:1820-6.

2. Murphy CC, Singal AG, Baron JA, Sandler RS, Simmons HC, Cancer C, et al. Decrease in Incidence of Young-Onset Colorectal Cancer Before Recent Increase. Gastroenterology. 2019;155:1716-9.

3. Boeckel TP Van, Gandra S, Mpp AA, Caudron Q, Grenfell PBT, Levin PSA, et al Global antibiotic consumption 2000 to 2010: an analysis of national pharmaceutical sales data. Lancet Infect Dis [Internet]. 2014;14:742-50.

4. Zhang J, Haines C, Watson AJM, Hart AR, Platt MJ, Pardoll DM, et al. Oral antibiotic use and risk of colorectal cancer in the United Kingdom, 1989-2012: a matched case-control study. 2019;68:1-8.

5. Hofseth LJ, Hebert JR, Chanda A, Chen H, Love BL, Pena MM, et al. Early-onset colorectal cancer: initial clues and current views. Nat Rev Gastroenterol Hepatol [Internet]. 2020. https://doi.org/10.1038/s41575-019-0253-4.

6. Patel SG, Ahnen DJ. Colorectal Cancer in the Young. Curr Gastroenterol Rep. 2018;20:15. https://doi.org/10.1007/s11894-018-0618-9. 
7. Simin J, Fornes R, Liu Q, Olsen RS, Callens S, Engstrand L, et al. Antibiotic use and risk of colorectal cancer: a systematic review and dose-response meta-analysis. Br J Cancer [Internet]. 2020;123:1825-32.

8. Sanyaolu LN, Oakley NJ, Nurmatov U, Dolwani S, Ahmed H. Antibiotic exposure and the risk of colorectal adenoma and carcinoma: a systematic review and meta-analysis of observational studies. Color Dis. 2019;22:858-70.

9. Perrott S, Laurie K, Laws K, Johnes A, Miedzybrodzka Z, Samuel L. Young-onset colorectal cancer in the North East of Scotland: survival, clinico-pathological features and genetics. BMC Cancer [Internet]. 2020;20:108.

10. Siegel RL, Miller KD, Goding Sauer A, Fedewa SA, Butterly LF, Anderson JC, et al. Colorectal cancer statistics, 2020. CA Cancer J Clin. 2020;70:145-64.

11. Ballester V, Rashtak S, Boardman L. Clinical and molecular features of youngonset colorectal cancer. World J Gastroenterol. 2016;22:1736-44.

12. Cercek A, Chatila WK, Yaeger R, Walch H, Fernandes GDS, Krishnan A, et al. A Comprehensive comparison of early-onset and average-onset colorectal cancers. J Natl Cancer Inst [Internet]. 2021. https://doi.org/10.1093/jnci/djab124.

13. Blaser MJ, Melby MK, Lock M, Nichter M. Accounting for variation in and overuse of antibiotics among humans. BioEssays. 2021;43:e2000163. https://doi.org/ 10.1002/bies.202000163. Epub 2021 Jan 6.

14. Dolk CK, Pouwels KB, Smith DRM, Robotham JV, Smieszek T. Antibiotics in primary care in England: which antibiotics are prescribed and for which conditions? J Antimicrob Chemother. 2018;73:2-10.

15. Butel M-J, Waligora-Dupriet A-J, Wydau-Dematteis S. The developing gut microbiota and its consequences for health. J Dev Orig Health Dis. 2018;9:590-7. https://doi.org/10.1017/S2040174418000119. Epub 2018 Mar 22.

16. Bailey LC, Forrest CB, Zhang P, Richards TM, Livshits A, DeRusso PA. Association of antibiotics in infancy with early childhood obesity. JAMA Pediatr. 2014;168:1063-9.

17. Allwell-Brown G, Hussain-Alkhateeb L, Kitutu FE, Strömdahl S, Mårtensson A, Johansson EW. Trends in reported antibiotic use among children under 5 years of age with fever, diarrhoea, or cough with fast or difficult breathing across lowincome and middle-income countries in 2005-17: a systematic analysis of 132 national surveys from 73 countrie. Lancet Glob Heal. 2020;8:e799-807.

18. Center for Disease Control. Antibiotic use in the United States, 2018: Progress and Opportunities. US Department of Health and Human Services. 2018.

19. Bhate K, Lin LY, Barbieri J, Leyrat C, Hopkins S, Stabler R, et al. Is there an association between long-term antibiotics for acne and subsequent infection sequelae and antimicrobial resistance? A systematic review protocol. BMJ Open. 2020;10:e033662.

20. Public Health England. Research reveals levels of inappropriate prescriptions in England [Internet]. 2018. https://www.gov.uk/government/news/researchreveals-levels-of-inappropriate-prescriptions-in-england.

21. Zitvogel L, Daillère R, Roberti MP, Routy B, Kroemer G. Anticancer effects of the microbiome and its products. Nat Publ Gr [Internet]. 2017;15:465-78.

22. Whisner CM, Aktipis CA. The role of the microbiome in cancer initiation and progression: how microbes and cancer cells utilize excess energy and promote one another's growth. Curr Nutr Rep. 2019;8:42-51.

23. Goodwin AC, Destefano CE, Wu S, Huso DL, Wu X. Polyamine catabolism contributes to enterotoxigenic Bacteroides fragilis -induced colon tumorigenesis. PNAS. 2011;108:15354-9.

24. Kilkkinen $A$, Rissanen $H$, Klaukka $T$, Pukkala $E$, Heliövaara $M$, Huovinen $P$, et al. Antibiotic use predicts an increased risk of cancer. Int J Cancer. 2008;123:2152-5.

25. Friedman GD, Coates AO, Potter JD, Slattery M. Drugs and colon cancer. Pharmacoepidemiol Drug Saf. 1998;7:99-106.

26. Friedman GD, Jiang SF, Udaltsova N, Quesenberry CP, Chan J, Habel LA. Epidemiologic evaluation of pharmaceuticals with limited evidence of carcinogenicity. Int J Cancer. 2009;125:2173-8.

27. Wang J, Chang C. Infection, antibiotic therapy and risk of colorectal cancer: a nationwide nested case-control study in patients with Type 2 diabetes mellitus. Int J Cancer. 2014;967:956-67.

28. Dik VK, Oijen MGHVan, Smeets HM, Siersema PD. Frequent use of antibiotics is associated with colorectal cancer risk: results of a nested case-control study. Dig Dis Sci. 2016;61:255-64.

29. Armstrong D, Dregan A, Ashworth M, White P, McGee C, de Lusignan S. The association between colorectal cancer and prior antibiotic prescriptions: case control study. Br J Cancer [Internet]. 2020;122:912-7.

30. Didham RC, Reith DM, McConnell DW, Harrison KS. Antibiotic exposure and breast cancer in New Zealand. Breast Cancer Res Treat. 2005;92:163-7.

31. Boursi B, Haynes K, Mamtani R, Yang YX. Impact of antibiotic exposure on the risk of colorectal cancer. Pharmacoepidemiol Drug Saf. 2015;24:534-42.

32. Falagas ME, Walker AM, Jick $H$, Ruthazer $R, J$ G, Snydman DR. Late incidence of cancer after metronidazole user/non-user study. Clin Infect Dis. 1998;26:384-8.

33. University of Aberdeen. Primary Care Clinical Informatics Unit Research. The Institute of Applied Health Sciences. https:/www.abdn.ac.uk/iahs/research/ primary-care/pcciur/index.php. Accessed Date 2019-02-18.
34. Busby J, Murchie P, Murray L, Iversen L, Lee AJ, Spence A, et al. The effect of medications which cause inflammation of the gastro-oesophageal tract on cancer risk: a nested case-control study of routine Scottish data. Int J Cancer. 2017;140:1828-35.

35. Tran KT, McMenamin C, Hicks B, Murchie P, Thrift AP, Coleman HG, et al. Proton pump inhibitor and histamine-2 receptor antagonist use and risk of liver cancer in two population-based studies. Aliment Pharmacol Ther. 2018;48: 55-64.

36. Spence AD, Busby J, Murchie $P$, Kunzmann AT, McMenamin ÚC, Coleman HG, et al. Medications that relax the lower oesophageal sphincter and risk of oesophageal cancer: an analysis of two independent population-based databases. Int J Cancer. 2018;143:22-31.

37. Macfarlane TV, Lefevre K, Watson MC. Aspirin and non-steroidal anti-inflammatory drug use and the risk of upper aerodigestive tract cancer. $\mathrm{Br} \mathrm{J}$ Cancer. 2014;111:1825-59.

38. Dozois EJ, Boardman LA, Suwanthanma W, Limburg PJ, Cima RR, Bakken JL, et al. Young-onset colorectal cancer in patients with no known genetic predisposition: Can we increase early recognition and improve outcome? Medicine (Baltim). 2008;87:259-63.

39. Pottegård A, Hallas J. New use of prescription drugs prior to a cancer diagnosis. Pharmacoepidemiol Drug Saf. 2017;26:223-7.

40. Cao $Y$, Wu K, Mehta R, Drew DA, Song M, Lochhead $P$, et al. Long-term use of antibiotics and risk of colorectal adenoma. Gut. 2018;67:672-8.

41. Zhang J, Haines C, Watson AJM, Hart AR, Platt MJ, Pardoll DM, et al. Oral antibiotic use and risk of colorectal cancer in the United Kingdom, 1989-2012: a matched case-control study. Gut. 2019;68:1971-8.

42. Rafii F, Sutherland JB, Cerniglia CE. Effects of treatment with antimicrobial agents on the human colonic microfl ora. Therapeutics and Clinical Risk Management. 2008.

43. Khan NF, Perera R, Harper S, Rose PW. Adaptation and validation of the Charlson Index for Read/OXMIS coded databases. BMC Fam Pract. 2010;11:1.

44. Garcia-Albeniz X, Chan AT. Aspirin for the prevention of colorectal cancer. Best Pract Res Clin Gastroenterol. 2011;25:461-72.

45. Sangha S, Yao M, Wolfe MM. Non-steroidal anti-inflammatory drugs and colorectal cancer prevention. Vol. 81, Postgraduate Medical Journal. The Fellowship of Postgraduate Medicine; 2005. p. 223-7.

46. Hannan LM, Jacobs EJ, Thun MJ. The Association between cigarette smoking and risk of colorectal cancer in a large prospective cohort from the United States. Cancer Epidemiol Biomarkers Prev. 2009;18:3362-7.

47. Pedersen A, Johansen C, Grønbæk M. Relations between amount and type of alcohol and colon and rectal cancer in a Danish population based cohort study. Gut. 2003;52:861-7.

48. Raghunathan T, Lepkowski J, Van Hoewyk J, Solenberger P. A multivariate technique for multiply imputing missing values using a sequence of regression models. Surv Methodol. 2001;27:85-95.

49. Lu SSM, Mohammed Z, Häggström C, Myte R, Lindquist E, Gylfe $\AA$, et al. Antibiotics use and subsequent risk of colorectal cancer: a Swedish Nationwide Population-Based Study. J Natl Cancer Inst. 2021;00:1-9.

50. Dejea CM, Wick EC, Hechenbleikner EM, White JR, Mark Welch JL, Rossetti BJ, et al. Microbiota organization is a distinct feature of proximal colorectal cancers. Proc Natl Acad Sci USA [Internet]. 2014;111:18321-6.

51. den Besten G, van Eunen K, Groen AK, Venema K, Reijngoud D-J, Bakker BM. The role of short-chain fatty acids in the interplay between diet, gut microbiota, and host energy metabolism. J Lipid Res [Internet]. 2013;54:2325-40.

52. Fedak KM, Bernal A, Capshaw ZA, Gross S. Applying the Bradford Hill criteria in the 21st century: how data integration has changed causal inference in molecular epidemiology. Emerg Themes Epidemiol. 2015;12:1-9.

53. Kasselman LJ, Vernice NA, DeLeon J, Reiss AB. The gut microbiome and elevated cardiovascular risk in obesity and autoimmunity. Atherosclerosis [Internet]. 2018;271:203-13.

54. Myers B, Brownstone N, Reddy V, Chan S, Thibodeaux Q, Truong A, et al. The gut microbiome in psoriasis and psoriatic arthritis. Best Pr Res Clin Rheumatol [Internet]. 2019;33:101494.

55. Sharma S, Tripathi P. Gut microbiome and type 2 diabetes: where we are and where to go? J Nutr Biochem [Internet]. 2019;63:101-8.

56. Bailey CE, Hu C-Y, You YN, Bednarski BK, Rodriguez-Bigas MA, Skibber JM, et al. Increasing disparities in age-related incidence of colon and rectal cancer in the United States, 1975-2010. JAMA Surg. 2015;150:17-22.

57. Chumduri C, Gurumurthy RK, Zadora PK, Mi Y, Meyer TF. Chlamydia infection promotes host DNA damage and proliferation but impairs the DNA damage response. Cell Host Microbe [Internet]. 2013;13:746-58.

58. Heijne JCM, van Liere GAFS, Hoebe CJPA, Bogaards JA, van Benthem BHB, Dukers-Muijrers NHTM. What explains anorectal chlamydia infection in women? Implications of a mathematical model for test and treatment strategies. Sex Transm Infect [Internet]. 2017;93:270-5. 
59. Cisyk AL, Nugent Z, Wightman RH, Singh H, McManus KJ. Characterizing microsatellite instability and chromosome instability in interval colorectal cancers. Neoplasia [Internet]. 2018;20:943-50.

60. Akimoto N, Ugai T, Zhong R, Hamada T, Fujiyoshi K, Giannakis M, et al. Rising incidence of early-onset colorectal cancer-a call to action. Nat Rev Clin Oncol [Internet]. 2021;18:230-43.-

61. De MouraM, Van. HoutenB. An update on the genotoxicity and carcinogenicity of marketed pharmaceuticals with reference to in silico predictivity: a review article. Environ Mol Mutagen [Internet]. 2010;405:391-405.

62. Attur MG, Patel RN, Patel PD, Abramson SB, Amin AR. Tetracycline up-regulates COX-2 expression and prostaglandin E2 production independent of its effect on nitric oxide. J Immunol [Internet]. 1999;162:3160-7.

63. Dixon DA, Blanco FF, Bruno A, Patrignani P. Mechanistic aspects of COX-2 expression in colorectal neoplasia. Recent Results Cancer Res. 2013;191:7-37.

64. Bardou M, Barkun AN, Martel M. Obesity and colorectal cancer. Gut [Internet]. 2013;62:933 LP-947.

65. Schulfer A, Blaser MJ. Risks of antibiotic exposures early in life on the developing microbiome. PLoS Pathog [Internet]. 2015;11:e1004903-e1004903.

66. Axelsson M. Report on personality and adherence to antibiotic therapy: a population-based study. BMC Psychol. 2013;1:3-8.

67. StataCorp. Stata Statistical Software: Release 15. College Station: StataCorp LLC; 2017

\section{ACKNOWLEDGEMENTS}

We wish to thank PCCIUR, University of Aberdeen, especially Artur Wozniak, for extracting the data and performing case-control matching.

\section{AUTHOR CONTRIBUTIONS}

Study concept and design: all authors. Statistical analysis and interpretation of data: RM and CC. Literature review: SP. Initial drafting of the manuscript: SP and RM. Data interpretation and editing of the manuscript: SP, RM, CC, PM, CM and LS. All authors approved the final manuscript.

\section{FUNDING INFORMATION}

This work is supported by Cancer Research UK (reference C37316/A25535).

\section{ETHICAL APPROVAL AND CONSENT TO PARTICIPATE}

The study was approved by the Research Applications and Data Management Team at the University of Aberdeen and Queen's University Belfast, School of Medicine,
Ethics Committee (reference number: 18.02v2). According to Caldicott principles patients registered at participating practices were made aware that their anonymous data could be used in research and had the opportunity to withdraw should they wish. The study was performed in accordance with the Declaration of Helsinki.

\section{CONSENT FOR PUBLICATION}

Not applicable.

\section{COMPETING INTERESTS}

The authors declare no competing interests.

\section{ADDITIONAL INFORMATION}

Supplementary information The online version contains supplementary material available at https://doi.org/10.1038/s41416-021-01665-7.

Correspondence and requests for materials should be addressed to Leslie Samuel.

Reprints and permission information is available at http://www.nature.com/ reprints

Publisher's note Springer Nature remains neutral with regard to jurisdictional claims in published maps and institutional affiliations.

(i) Open Access This article is licensed under a Creative Commons Attribution 4.0 International License, which permits use, sharing, adaptation, distribution and reproduction in any medium or format, as long as you give appropriate credit to the original author(s) and the source, provide a link to the Creative Commons license, and indicate if changes were made. The images or other third party material in this article are included in the article's Creative Commons license, unless indicated otherwise in a credit line to the material. If material is not included in the article's Creative Commons license and your intended use is not permitted by statutory regulation or exceeds the permitted use, you will need to obtain permission directly from the copyright holder. To view a copy of this license, visit http://creativecommons. org/licenses/by/4.0/.

(c) The Author(s) 2021 